\title{
Depression was associated with decreased survival for hospital patients who were seriously ill
}

\author{
Roach MJ, Connors AF, Dawson NV,et al for the SUPPORT Investigators. Depressed mood and survival in seriously ill hospitalized \\ adults. Arch Intern Med 1998 Feb 23;158:397-404.
}

\section{Question}

For hospital patients who are severely ill, is self reported depression associated with mortality after adjusting for functional status and severity of illness?

\section{Design}

Cohort study with 4 year follow up (Study to Understand Prognoses and Preferences for Outcomes and Risks of Treatments [SUPPORT]).

\section{Setting}

5 tertiary teaching hospitals in the US.

\section{Participants}

3529 patients (median age $63 \mathrm{y}$, median education level $12 \mathrm{y}$, $58 \%$ men, $78 \%$ white, $52 \%$ married) admitted to hospital with a serious illness. The projected 6 month survival for the group was $50 \%$. Exclusion criteria were not speaking English; having AIDS, head trauma, or burns; being pregnant; $<18$ years old; expected hospital admission $<72$ hours; death within 48 hours of admission; or transfer from another hospital.

\section{Assessment of risk factors}

Depressed mood was measured using the shortened version of the Profile of Mood States depression scale. Severity of illness was measured by the acute physiology subscale of the Acute Physiology and Chronic Health Evaluation (APACHE) III scale, number of comorbid conditions present at hospital admission, and a study specific scale that used clinical indicators (SUPPORT model). Other risk factors were age, sex, marital status, years of education, activities of daily living, and primary diagnosis.

Main outcome measure

Patients and families were contacted and national databases were used to calculate survival time from date of admission to the study.

\begin{abstract}
Main results
More serious depression was associated with younger age $(\mathrm{p} \leqslant 0.001)$, worse levels of physical functioning $(\mathrm{p}=0.001)$, and greater severity of illness $(p=0.001)$. When all risk factors were simultaneously entered into a hazards model predicting survival, self reported depressed mood was independently related to increased mortality as were being a man, more comorbid illnesses at baseline, decreased activities of daily living, increased age and 6 month estimate of survival (table).
\end{abstract}

\section{Conclusion}

Depressed mood was independently related to mortality of hospital patients after adjusting for severity of illness, physical functioning, and patient characteristics.

Risk factors associated with mortality of hospital patients who were severely ill (hazards ratio for each unit of change)

\begin{tabular}{lll}
\hline Variable & Hazard ratio & $95 \%$ CI \\
\hline Sex (being a man) & 1.16 & 1.04 to 1.29 \\
Depressed mood score & 1.13 & 1.07 to 1.20 \\
Increased number of comorbid illnesses & 1.13 & 1.08 to 1.18 \\
Decreased activities of daily living & 1.10 & 1.06 to 1.13 \\
Age (for each 10 y increase) & 1.07 & 1.02 to 1.11 \\
SUPPORT model 6 month survival & 0.64 & 0.57 to 0.71 \\
\hline
\end{tabular}

Source of funding: Robert Wood Johnson Foundation.

For correspondence: $\operatorname{Dr} M J$ Roach, Spinal Cord Research, Rammelkamp Building R230, MetroHealth Medical Center, 2500 MetroHealth Drive, Cleveland, OH 44109-1998, USA. Fax +1 2167788782

\section{Commentary}

Previous research has shown that depression, poor functional status, and severity of illness are associated with mortality. ${ }^{1}$ It has been unclear, however, whether depression is independently associated with mortality or whether it is simply closely associated with disease severity. The study by Roach et al makes 2 important contributions: firstly, it confirms that poor functional status and greater severity of illness are indeed associated with worse depressed mood scores; and secondly, it determines that depressed mood has an independent effect on mortality. They found that with every unit increase in depressed score (range of scores: $0-4$ with higher score signifying more depression) the odds of mortality increased by $13 \%$.

Strengths of the study are (1) the inclusion of a demographically and medically diverse group of acutely ill hospital patients which increases the generalisability of the study findings and (2) the use of a powerful statistical model that permitted testing of the independent effect of depression on survival. Limitations were the exclusion of patients who were too severely ill to complete the depression interview, and the inability to make a causal link between depression and mortality because data regarding depression were not collected before hospital admission.

Rather than attempting to diagnose depression in terms of psychiatric illness, Roach $e t$ al have tested the hypothesis that feeling depressed can affect recovery. They attempt to consider the patient as an entity rather than as a condition. The depressed mood inventory takes only a few minutes to apply and is easy to score. It determines the extent to which patients feel unhappy, sad, blue, hopeless, discouraged, miserable, helpless, and worthless. The authors have shown that a simple inventory can assess depressed mood and identify those severely ill hospital patients at increased risk of mortality. Further research is needed to determine whether interventions aimed at relieving depression in these patients reduces the risk of death.

John Dyer, RMN, MA

Team Leader, Elderly Mental Health Dorset Community NHS Trust

Dorchester, $U K$

1 Covinsky KE, Fortinsky RH, Palmer RM, et al. Relation between symptoms of depression
and health status outcomes in acutely ill and health status outcomes in acutely ill 1997;126:417-25. 